\title{
Social Representations of Breastfeeding in Health Sciences Students: A First Step to Strengthening their Training
}

\section{Gabriela Alejandra Grover-Baltazar}

Universidad de Guadalajara Centro Universitario de Ciencias de la Salud

\section{Ana Sandoval-Rodríguez}

Universidad de Guadalajara Centro Universitario de Ciencias de la Salud

\section{Gabriela Macedo-Ojeda}

Universidad de Guadalajara Centro Universitario de Ciencias de la Salud

\section{Gabriel Chavira-Trujillo}

Universidad de Guadalajara Centro Universitario de Ciencias de la Salud

Marco Julián Corona-Ortíz

Technological University Dublin - Dublin City Center Campus: Technological University Dublin

\section{Martha De Alba}

Universidad Autonoma Metropolitana Iztapalapa

\section{Barbara Vizmanos ( $\sim$ bvizmanos@yahoo.com.mx)}

Universidad de Guadalajara Centro Universitario de Ciencias de la Salud https://orcid.org/0000-00030680-0802

\section{Research Article}

Keywords: breastfeeding experience, breastfeeding knowledge, breastfeeding promotion, lactation education, qualitative Research, Social Perception, Health Education, México

Posted Date: May 5th, 2021

DOI: https://doi.org/10.21203/rs.3.rs-453631/v1

License: (c) (i) This work is licensed under a Creative Commons Attribution 4.0 International License. Read Full License 


\section{Abstract}

\section{Background}

Breastfeeding is a complex phenomenon involving biological, affective, and socio-cultural aspects. Its definition is built by a diversity of beliefs, attitudes, traditions, and myths. Being aware of the connection between the biological and socio-cultural concepts into the Social Representations of breastfeeding in health sciences, will allow us to have a better comprehension of their attitudes/behavior towards breastfeeding. Therefore, the objective of this study is to describe the Social Representations on breastfeeding among Mexican health sciences students.

Methods

This study was carried out based on the structuralist approach of the Social Representations Theory. Data collection was done with free-listing questionnaires with a "breastfeeding" as inducer word among nutrition, medical, and nursing undergraduate students $(n=124)$. The analyses used were: similitude of words and of the meanings of words, prototypical and categorical analysis.

Results

The findings suggest that the structure of the social representation is composed of breastfeeding components (baby, mother and milk), affective (attachment, love and link), biological (nutrition, breasts and health), and socio-cultural elements (taboo, responsibility and economic). Within the nucleus, only instrumental elements are found, whereas in the peripheries, biological, affective, and socio-cultural elements are observed.

Conclusions

The structure of the social representations of breastfeeding in Mexican undergraduate students in health sciences focuses on instrumental aspects, leaving the background elements with more scientific meanings typical of their training. These results, replicated in different contexts, will allow the creation of educational strategies adapted to strengthen the breastfeeding training of health students to improve breastfeeding promotion in the society.

\section{Background}

Breastfeeding (BF) is considered as the standard diet for infants, as it is the ideal food for their growth and healthy development throughout their childhood (1). Multiple BF benefits in the short and long term, have been described for the infant and mother $(2,3)$.

The World Health Organization (WHO) and the United Nations International Children's Emergency Fund (UNICEF) recommend that infants be exclusively breastfeed from birth until six months of life. Complementary foods are recommended to be introduced after sixth month of age together with breastfeeding up to 2 years of age or beyond (1). 
Despite the numerous benefits that BF has in health, the world's rate of infants under 6 months being exclusively breastfed is only $41 \%$ (4). In Mexico, the prevalence rate of exclusive breastfeeding has been increasing over the years, reaching $28.93 \%$ in 2018 (5), while in 2012 it was only $14.5 \%$ (6). Despite this increment, it is still far from the global target rate for 2030 of $70 \%$ of mothers providing exclusive breastfeeding (4).

Multiple barriers can obstruct an adequate establishment of BF. In healthcare services, the lack of breastfeeding-trained health professionals becomes crucial since the healthcare workforce must provide evidence-based information to promote BF. Moreover, it has been shown that support from health professionals and $\mathrm{BF}$ experts, during $\mathrm{BF}$ period can increase the duration of $\mathrm{BF}(7,8)$. Otherwise, untrained healthcare workers service for breastfeeding mothers could be one of the added causes influencing mother decision to not continue BF.

Breastfeeding is a social phenomenon that has been practiced for centuries and involves biological, affective, and socio-cultural aspects (9). Its knowledge has been shaped by diverse traditions, myths, attitudes, beliefs, and cultural concepts, defined and changed through time $(10,11)$. Hence, it becomes relevant to know the social constructs about BF in health sciences students. Since healthcare workers take part of the health care for mothers and their infants before, during, and after birth, it is crucial they exhibited the appropriate attitude in $\mathrm{BF}$ promotion.

Social representations theory specifies how collective cognitions are created and transformed through communication, focusing on the socio-cognitive mechanisms involved, and is used for the study of social constructs. Besides, according to Moscovici, a social representation (SR) is a set of thoughts shared by a social group contributing to understanding the individuals' reality (12). A SR has also been defined as the set of cognitions that individuals have towards an object, which is organized through multiple relationships (13). Importantly, social representations are social products derived from interaction and it always develops, circulates and is transformed in relation to other social representations. For Abric (1994), a SR is formed by a set of information, beliefs, opinions, and attitudes towards a social object. These elements are organized and prioritized in relation to a central core and a peripheral system. The core is formed by two dimensions: a normative dimension, in which socio-affective and ideological elements are expressed, and a functional dimension, which is operative (14). The core's function is to determine the organization and meaning of a SR. It is characterized by being resistant to change, as it is formed by the most consensual notions of the social object. It is the most stable area of a SR. On the contrary, the peripheral zone of a SR is prone to change; while the frequency of words forming it is high, the level of influence in a SR is considered to be low. This zone connects the core to the social context $(14,15)$.

Based on these premises, the objective of present research it explore the structure of Social Representations on breastfeeding among Mexican students of the Health Sciences.

\section{Methods}

Study design: The present qualitative study is based on the Social Representations Theory and its structuralist approach $(13,14,16)$. 
Study setting: The study was carried out at the University Center of Health Sciences (CUCS) of the University of Guadalajara (UdeG). The UdeG is made up of a group of University Centers distributed throughout the state of Jalisco. It is a public university leader in the academic training of human resources (17). The CUCS UdeG is part of this state network, where health professionals are trained in medicine, nursing, and nutrition, among others. These three educational programs represented in $2019,67.6 \%$ of the total undergraduate population enrolled in this center, equivalent to 4,298 medical students, 2,028 nursing students, and 999 nutrition students (18).

Participants: The study was conducted at student health sciences from CUCS of UdeG Nursing, Nutrition, and Medicine Bachelor Degrees were considered because these disciplines are in direct contact with mothers before, during, and after giving birth, in Jalisco, Mexico. Information was collected within November 2017 to March 2018.

Sampling: Non-probability sampling was used (19). Selection criteria consider students who attended the second semester onwards in Nursing, Nutrition, or Medicine academic programs. Sex was not a selection criterion.

Data collection: Students were invited to voluntarily participate and asked to sign an informed consent. Also, participants completed a socio-demographic and academic questionnaire. Free-lists technique was used to know the elements of participants' social representations based on the inductive concept "breastfeeding". Participants wrote down five words or expressions that come to their mind, along with the reason why they chose them $(14,15)$.

Data analysis: Three types of analyses were carried out: similitude applied to words and meanings, prototypical and categorical analysis. Analyses were performed using the 07 . Alpha2 version of the IRaMuteQ software.

Firstly, analysis of similitude was applied to explore co-occurrence of words. The co-occurrence index allows to identify the coincidence of words, showing graphically the number of times that each element was mentioned in the group of participants (20). Furthermore, by applying the similitude analysis to the participants' definitions of their chosen words, additional information was identified. This information contributed to discuss the elements forming the SR.

Secondly, a prototypical analysis was used to identify the structure of the SR based on the participant's words (16). This analysis considers all the words that were mentioned in the free lists focusing in two indicators: the word occurrence (WO) (number of times that a concept was mentioned); and the occurrence average $(O A)$ (the place in which a word was mentioned) $(14,16)$.

By intersecting both indicators, a table (2x2) classifying each indicator as high (+) or low (-) was generated. This classification is organized in four zones describing the structure of one SR: the central core (WO + OA-); contrast zone (WO-, OA-), and the first and second peripheries (WO+, OA+, WO-, OA+). The words with the highest frequency and first mentioned are in the central core; whilst in the contrast zone are the words that were first mentioned but with a lower frequency than those in the central core. The words that have not been 
mentioned within the top places but relevant by their frequency are ubicated in the peripheral zones (first zone); other words with low frequency and at the bottom are included in this zone, as well.

Lastly, to do the categorical analysis, only the list of words forming the of prototypical analysis was used. All the words were grouped based on their semantic similarity, the central core words which worked as the base to the SR's thematic categories.

\section{Results}

124 participants were included. Majority of participants were women (75.8\%), from Medicine academic degree $(39.5 \%)$ and average age was $20(+/-5.1)$ years old. Table 1 describes with more detail the characteristics of the sample.

Table 1

Characteristics of the students $(n=124)$

\begin{tabular}{|llll|}
\hline Degree & Women & Men & Total \\
\cline { 2 - 4 } & $\mathbf{n}(\%)$ & $\mathbf{n}(\%)$ & $\mathbf{n}(\%)$ \\
\hline Medicine & $31(63.3)$ & $18(36.7)$ & $49(39.5)$ \\
\hline Nutrition & $34(81.0)$ & $8(19.0)$ & $42(33.9)$ \\
\hline Nursing & $29(87.9)$ & $4(12.1)$ & $33(26.6)$ \\
\hline Total & $94(75.8)$ & $30(24.2)$ & $124(100.0)$ \\
\hline
\end{tabular}

Free-lists analysis showed a total of 608 words or expressions. Among them, 235 were different $(38.65 \%)$, and 373 were similar (61.35\%). The results show the consensus reached. Eleven participants did not complete the free-lists: one participant did not write the fourth word of the list of five; ten more participants did not write the fifth word. This represents $2 \%$ of missing data by omission, being within the admissible range required to use these participant's information (21).

a). Analysis of Similitude

The analysis of similitude for the words that were mentioned in the free lists is shown in Fig. 1. The coincidence showed the word "baby" as the one with the highest co-ocurrence, making it the main element in the graph.

\section{Figure 1. Graphic representation of the similitude of the words related to breastfeeding.}

Within this analysis Fig. 1, the words "mother" and "milk" occupy the second place, indicating a similar coocurrence degree, followed by the word "food". A second group of words with high co-occurrence degree with the word "nutrition" organizes another set of words, such as "love", "attachment" and "health"; these words are connected to other elements, as well.

Some semantic units related to the breastfeeding SR were organized according to the meaning of the expressed words Fig. 2. This analysis showed that the students' SR is organized mainly by elements like 
"baby", "mother", "breastfeeding", "milk", "food" and "nutrients". These notions have high co-occurrence levels among the participants. Furthermore, these words are connected to other elements, providing new approaches to breastfeeding SR in each one of the semantic units. As shown in Fig. 2, "baby" is organising the most substantial semantic unit, organising words like "development", "to provide", "breastfeeding", "mother's milk", "immune system", "food", "growth", "to breastfeed", "health", "to need", "better", and "unique".

Figure 2. Graphic representation of the meaning of the words related to breastfeeding.

The word "mother" has a key semantic unit within these connections, and provides an important meaning within the SR. The elements connecting this notion are: "child", "bond", "love", "link". The rest of the notions that emerged from this graph are connected to other words that provide different approaches to SR, as well.

b). Prototypical Analysis

The prototypical analysis organizes a $2 \times 2$ matrix of the SR social representation, by pondering the words by order of appearance (evocation rank) and number of mention (evocation frequency). The present study had a minimum evocation frequency of two, and the evocation rank was 2.79 , while 56 different words were evoked Table 2. 
Table 2

Prototypical Analysis of the Social Representations on Breastfeeding $(n=124)$.

\section{Evocation rank $\leq 2.79$}

Central Core

Evoked term

Frequency

$\geq 7.4$

53

$\begin{array}{ll}\text { Baby } & 53 \\ \text { Mother } & 33\end{array}$

Frequency ${ }^{a}$

38

33

Nutrition

28

16

14

8

Attachment

Contrast elements

Evoked term

Breast-feed
Antibodies
Life

6

5

5

Frequency $^{a}$ average $^{b}$

Freqcuency $\leq 7.4$ average $^{\mathrm{b}}$

2.5

2.5

2.4

2.4

2.6

2.5

2.2

2.2

2.6

2.4
Evocation

\section{Evocation rank $>2.79$}

\section{First periphery}

Evocation Evoked term

2.6

2.2

2.2

2

2.7

2.7

2.5

2

\section{Second Periphery}

Evoked term
Frequency ${ }^{\mathrm{a}}$

Evocation average $^{b}$

3.2

2.8

3.1

3.2

3.4

Link

Natural

8

2.9

Frequency $^{a}$

Evocation average $^{b}$

\begin{tabular}{llllll|}
\hline Connection & 5 & 2.6 & Sweetie & 6 & 3.7 \\
\hline Nutrients & 5 & 2.2 & Development & 5 & 3.8 \\
\hline Meal & 4 & 2.2 & Immunity & 5 & 2.8 \\
\hline Pregnancy & 4 & 2 & Techniques & 4 & 3 \\
\hline Nutritious & 3 & 2.7 & Motherhood & 4 & 3 \\
\hline Important & 3 & 2.7 & Defenses & 4 & 2.8 \\
\hline Awareness & 2 & 2.5 & Union & 4 & 3.8 \\
\hline Necessary & 2 & 2 & Care & 4 & 3 \\
\hline
\end{tabular}

Legend:

a. Number of times (frequency) in which the studied sample evoked each term.

b. Each word can appear in positions 1 to 5 (first or last of the five words evoked). This data is the average of the value of a given item's position in the evocations of the same item made by the subjects in the sample. 


\begin{tabular}{|c|c|c|c|c|c|c|}
\hline & \multicolumn{3}{|c|}{ Evocation rank $\leq 2.79$} & \multicolumn{3}{|c|}{ Evocation rank $>2.79$} \\
\hline & Normal & 2 & 2.5 & Woman & 3 & 4 \\
\hline & Newborn & 2 & 1 & Taboo & 3 & 3.7 \\
\hline & Mother and son & 2 & 1.5 & Responsibility & 3 & 5 \\
\hline & $\begin{array}{l}\text { Immunoglobulin } \\
\operatorname{lgA}\end{array}$ & 2 & 2 & Prevention & 3 & 3.3 \\
\hline & & & & Pain & 3 & 4 \\
\hline & & & & Increase & 3 & 3.3 \\
\hline & & & & $\begin{array}{l}\text { Breast cancer } \\
\text { prevention }\end{array}$ & 3 & 4.3 \\
\hline & & & & Wellbeing & 2 & 3.5 \\
\hline & & & & $\begin{array}{l}\text { Immune } \\
\text { system }\end{array}$ & 2 & 3.5 \\
\hline & & & & Pink & 2 & 5 \\
\hline & & & & Benefits & 2 & 4 \\
\hline & & & & $\begin{array}{l}\text { Mammary } \\
\text { glands }\end{array}$ & 2 & 4 \\
\hline & & & & Fundamental & 2 & 3 \\
\hline & & & & Contact & 2 & 3 \\
\hline & & & & Nourish & 2 & 3 \\
\hline & & & & Economic & 2 & 4.5 \\
\hline & & & & Nipple & 2 & 3 \\
\hline \multicolumn{7}{|l|}{ Legend: } \\
\hline \multicolumn{7}{|c|}{ a. Number of times (frequency) in which the studied sample evoked each term. } \\
\hline $\begin{array}{l}\text { b. Each worc } \\
\text { average of } \mathrm{tl} \\
\text { the sample. }\end{array}$ & $\begin{array}{l}n \text { appear in positi } \\
\text { alue of a given it }\end{array}$ & & $\begin{array}{l}\text { or last } \\
\text { the ev }\end{array}$ & $\begin{array}{l}\text { ive words evoke } \\
\text { of the same it }\end{array}$ & & $\begin{array}{l}\text { the } \\
\text { subjects in }\end{array}$ \\
\hline
\end{tabular}

\section{Table 2. Prototypical Analysis of the Social Representations on Breastfeeding $(n=124)$.}

As shown in Table 2, the central core is formed by the notions of "baby", "mother", "milk", "nutrition", "breasts", "health" and "attachment". For the students of the health sector these notions define and give coherence to the Social Representations of breastfeeding. Based on this analysis notions like "baby", "mother", and "attachment" are identified as the normative instrumentalist factors. On the other, "nutrition", "breasts", "health" and "milk" are functional elements of breastfeeding's SR. 
Some of the elements within the first peripheral zone are: "love", "food", "protection", "bond" and "natural". These words seem related to expression of feelings or demonstrations of affection that are born from breastfeeding. These elements composed the main themes above the central core, except for the word "natural", which adds a different and new meaning to the previous elements.

In the second peripheral zone, the largest number of the SR's words is found, as well as normative and functional elements. These elements are built upon a scientific base, and are associated to the benefits of breastfeeding, such as "development", "growth", "immunity", "care", "prevention", "immune system", and "benefit". These elements are anchored to the specialized knowledge acquired in health sciences related studies. Other founded elements are related to socio-cultural aspects, such as "normal", "important", "techniques", "economic", "awareness", "responsibility", "woman", "pink" "maternity". These words describe actions, qualities and behaviours inherent to breastfeeding, and contributed to the normative and functional elements.

Within the contrast zone, we founded words like "breastfeeding", "antibodies", "life", "connection", "nutrients", "food", "pregnancy", "nutritious", "important", "awareness" and "necessary". These elements are important for the SR, as they are considered elements with a high potential for change to turn into central core elements.

The elements afore mentioned contribute to the understanding of the structure and contents of the participant's Social Representation of breastfeeding.

C). Categorical Analysis

The set of words resulting from the prototypical analysis ( 56 words) were used to do the categorical analysis and were further organized in seven categories. These categories are meant to interpret dimensions of breastfeeding's SR by students that participated in the study. In Table 3 the categories and words are detailed. 
Table 3

Thematic categories of the social representation of breastfeeding in health students.

\begin{tabular}{|c|c|}
\hline $\begin{array}{l}\text { Category } \\
\text { name }\end{array}$ & Words mentioned by the participants \\
\hline Baby & Baby (53), Newborn (2) \\
\hline Mother & Mother (38), Motherhood (4), Pregnancy (4), Woman (3) \\
\hline $\begin{array}{l}\text { Affective } \\
\text { bond }\end{array}$ & $\begin{array}{l}\text { Love (22), Protection (11), Link (9), Attachment (8), Bound (7), Sweetie (6), Connection } \\
\text { (5), Union (4), Care (4), Mother and son (2), Contact (2) }\end{array}$ \\
\hline Feeding & $\begin{array}{l}\text { Milk (33), Nutrition (28), Feeding (22), Food (9), Colostrum (7), Breast-feed (6), Nutrients } \\
\text { (5), Meal (4), Nutritious (3), Nourish (2) }\end{array}$ \\
\hline Health & $\begin{array}{l}\text { Health (14), } 6 \text { months exclusive (6), Antibodies (5), Immunity (5), Development (5), } \\
\text { Defenses (4), Prevention (3), Breast cancer prevention (3), Immune system (2), IgA } \\
\text { Immunoglobulin (2), Benefits (2) }\end{array}$ \\
\hline Body & Breasts (16), Pain (3) Mammary gland (2), Nipple (2) \\
\hline $\begin{array}{l}\text { Sociocultural } \\
\text { aspects }\end{array}$ & $\begin{array}{l}\text { Natural (8), Life (5), Techniques (4), Taboo (3), Responsibility (3), Important (3), Increase } \\
\text { (3), Normal (2), Fundamental (2), Necessary (2), Wellbeing (2), Economic (2), Awareness } \\
\text { (2), Pink (2) }\end{array}$ \\
\hline d: Acc & $\begin{array}{l}\text { to the prototypical analysis, the number of times the word has been mentioned is } \\
\text { theses. }\end{array}$ \\
\hline
\end{tabular}

The perspectives of breastfeeding showed the meaning of lactation's social representation. One of the emerging perspectives, "mother", connects words around the social and biological role of the mother during the period of breastfeeding. The perspective categorized as "affective bond" connects words defining breastfeeding as a practice where emotions and feelings are crucial to the connection between mother and her child. The "food" category refers to the nutritional characteristics that human milk provides to the infant, containing words like "nourishing", "feeding", and "nutrients". Further developing breastfeeding SR, the category of "sociocultural aspects" provides a perspective of lactation defined by words like "nature", "normal", and "important" for "life", including concepts like "responsibility", and where the elements of "economy" and "taboo" become relevant. Lastly, other perspectives define breastfeeding as "healthy", and involved elements of the "body".

Based on this analysis, the main categories defining the social representation of the students are "feeding" and "affective bond" Fig. 3. On the other hand, "milk" and "nutrition", as well as the act of "feeding" are closely linked to the love a mother provides to the baby through her milk.

\section{Figure 3. Thematic categories of the social representations of breastfeeding in health student.}

Legend: The weight of each category is the total number of words that have been mentioned.

Furthermore, a relation among "feeding" and "affective bond" was found. Both categories influence more to the SR of breastfeeding among the students of nutrition, medicine, and nursing, in comparison to the technical knowledge, or the biologistic sense of scientific-based arguments supporting breastfeeding. 
Participants considered that women have not make the choice of breastfeed even it is considered as natural, normal and essential for the baby. It is perceived by them as a responsibility and a self-awareness that must be developed by the mother.

\section{Discussion}

The present study describes and identifies the structure and organization of the main elements that forms breastfeeding SR in a health sector student. After analysing the elements of the SR, it is possible to create models to approach the beliefs and practices related to breastfeeding.

It is not a new idea that breastfeeding is perceived as a comprehensive practice based on biological, psychological and social components. There is evidence than seems consistent with the presented results even that previous studies explored breastfeeding in other contexts $(9,11,22,23)$.

The concepts of "baby", "mother", "milk" and "nutrition" are elements founded in the student social representation of breastfeeding. These elements are key to breastfeeding, and considered to be valid in any cultural context; specifically, the elements of "baby" and "mother", as they are perceived as the main actors in the breastfeeding practice.

While the notion of "milk" is an indispensable element of breastfeeding, "nutrition" is defined as a characteristic and functional notion of it. These findings are similar to those presented in a study including breastfeeding Brazilian mothers where the notions defining the SR were "baby", "milk", and "food"(22).

Two main elements given by participants were the words: "breast" (referring to mammary glands) and "health" (referring to healthy). Considering their background training, it is logical that the information and knowledge they received about the multiple and documented benefits to human health of breastfeeding influenced them to answer these, and place this notion within the central core. The word "mother" is considered as a crucial element of the SR given its position into the prototypical analysis, and the concurrence index into the similitude analyses.

In other studies, it has also been linked to words that convey affection. Peruvian and Ecuadorian women speak of the importance of BF, in affective terms, perceiving it as a "transmitter of affection", where affection, love and the bond that occurs between mother and child during breastfeeding is the most important $(11,24)$. The present study founded that the notions describing the affective bond created during the breastfeeding period can be connected to nutritional aspects, as well. Based on the analysis of similitude, "nutrition" is the connection for other notions related to affection. It is perceived that the health sciences' students do not consider breastfeeding only as a period that creates an affective bond; they also seem to consider it as key to the infant's nutrition.

Other studies that were carried out in breastfeeding mothers in countries like Brazil (22), Peru (11), Colombia (9), and Spain (23), have presented similar findings. These studies showed that one of the main reasons given by the mothers to breastfeed is associated to immunological and nutritional elements. Mothers consider human milk as the best food for a healthy growth and development of their infants. The present study found elements in connection to the same notions "feeding", "nutrients", "nutritional", and "food". The 
notions found in connection to "health" were "anti-bodies", "immune system", "development", "growth", and "benefits".

A number of studies on breastfeeding have focused on the biological aspect of it, highlighting its benefits to the infant's health and centring on nutritional components $(2,25)$. However, it is necessary to further explore in detail the sociocultural and psychosocial aspects of breastfeeding to understand it in different contexts. On that line, WHO has advised to acknowledge the psychosocial benefits of breastfeeding, especially for the mother-child dyad (26).

While the present study founded that the psychosocial benefits are part of the SR of breastfeeding in the participants, it has found that they were not present in its central core, being part of the peripheral zones only. This has come to attention, since in the last years the psychosocial and cultural elements of breastfeeding have been constantly used as an element to promote and educate on breastfeeding.

Based on these findings, the fore mentioned campaigns are perceived to have impacted on the students' Social Representation. It is assumed that, if further information about breastfeeding is provided during their studies, the above-mentioned notions could become part of the central core.

The present study has found that the notion "baby" is placed at the centre of breastfeeding's SR. By playing her role, is noted that "mother" becomes an important notion around the central one. As the benefits that breastfeeding has for the mother are not clearly stated in that SR, it is concluded that maternity is seen from a social perspective, rather than from a biological point of view. From this notion, one more perspective is branched which considers breastfeeding an exclusively practice for women, who are considered the sole responsible of breastfeeding because of their motherhood. Motherhood is seen as a fundamental part of breastfeeding. However, participants only consider the binomial relation mother-child, because the SR express abstract elements only related to the breastfeeding practice not to the social construction that is implicit in motherhood.

In a study conducted by Pérez-Bravo (2017) among Spanish women, the mother was identified as a key element, as well, with a social function. Maternity is then defined as a sign of a feminine identity. Furthermore, breastfeeding is perceived as a characteristic of a good mother, and given this responsibility based on her womanhood. In the study, the mother was categorised as Good or bad based on her compliance with that role. It can be said that breastfeeding is related to a social representation of what means to be a good mother, an unattainable ideal to comply with. Recent studies based on gender perspective on maternity, have found that such ideal is still put on women $(27,28)$.

Breastfeeding is highly recommended by the WHO. However, considers that idealizing breastfeeding by health professionals can cause in mothers self-esteem problems, as well as feelings of guiltiness if they were unable to breastfeed Healthcare personal must provide information, guidance and support for the mothers, and their families, avoiding stigmatisation or guiltiness in women who decide not to breastfeed.

Interestingly, this work did not find negative notions connected to breastfeeding. However, is prominent that the notion of "pain" was mentioned two times (possibly in connection with sore nipple). There were not mentions of words such as: "breast pump", "hunger" or "the baby crying for hunger". The participants of this 
study did not mention words related to the difficulties that breastfeeding can represent to some mothers, neither to any learning process that could be needed. Remarkably, only two participants mentioned breastfeeding as a "taboo". Perhaps the exclusion of these elements within the students SR is because most of them have not gone through a professional nor a personal experience in relation to breastfeeding, and do not realize the range of difficulties that can be experienced.

Several studies have found $(23,29)$ that breastfeeding outcome is not exclusively influence by the mother decisions, emphasizing the importance of the role that the partner or father plays, as well as, extended family support (mothers, aunts, etc) and breastfeeding support groups. In the present study, we did not find any word referring to masculine or paternal figures in the SR of breastfeeding. It has been found that breastfeeding should not be considered exclusive to women (30,31); therefore, the lack of associations to male figures highlights the need to achieve gender equity. Also, participants restricted breastfeeding on mother's role, other family elements of external support were not part of the social representation. In consequence, it would be desirable to reinforce the curricula in order to raise students' awareness on social and familial influence on breastfeeding. Originally, we expected that participant students had a social representation of breastfeeding based on technic and scientific grounds, due to their health-related academic background. However, language related to notions of health and human body; were never expressed.

\section{Limitations}

The present study's main limitation is that using the free-lists technique only allows us to have an exploratory approach on the students' SR; other qualitative tools could obtain a more profound perspective of the SR in this population.

Another limitation is that the findings cannot be generalized to all students on our campus or University since the sample included only a portion of the students from three specific degrees. It is indispensable to include other campuses and degrees to improve our understanding of how to create cohesive and broader strategies that will allow students to accompany and promote breastfeeding to protect the mother, the child, the family, and the society, in general.

The present study's findings help understand social representations of breastfeeding in students of healthrelated sciences, which contribute to building educational strategies influencing their professional formation, the latter being the primary goal of this approach. This research allows us to contextualize the design of educational interventions and strategies focused on students from the health sector, such as nursing, nutrition, and medical career. Furthermore, to our knowledge, no other studies are exploring SR of breastfeeding in Mexican students.

\section{Conclusions}

The present document explores the SR of breastfeeding in students of health sciences. The central core is formed by the notion of persons and actions involved in the breastfeeding practice. It is also composed of elements describing and providing the SR of breastfeeding with specific functions. This work highlights that the students' educational processes have not contributed to making affective, biological, and social notions 
relevant enough to be part of the central core of SR. These notions were only found in peripheral zones of students' SR.

Therefore, we considered it indispensable to create specific educational strategies around breastfeeding in academic programs to transfer these affective and biological notions from peripheral areas into the central core, as recommended by international organisms like the WHO, UNICEF (1), and by the Academy of Breastfeeding Medicine (32).

The present study has found that it is essential to carry out interventions with health sciences students, focused on enhancing a broad understanding of breastfeeding. These interventions' objective should be to help them become aware of the positive impact of promoting breastfeeding as professionals of the health sector.

\section{Abbreviations}

Breastfeeding (BF)

Social Representation (SR)

Occurrence average (UA)

Word Occurrence (WO)

World Health Organization (WHO)

United Nations International Children's Emergency Fund (UNICEF)

\section{Declarations}

Ethics approval and consent to participate: This study started as a survey within the framework of educational processes in the University Center to analyze and improve breastfeeding education according to the Mexican National Strategies. Therefore, we prepared some exploring analysis and, the committees did not evaluate the study before the start of the project. We want to express that we used, at any moment, the International Ethical Guidelines for Health-related Research Involving Humans and the national guidelines for ethical aspects in the study. We always asked for the personal interest of the volunteers and explained to them the study, their optional participation, including absolute respect, as potential subordinates (without the presence of their teacher). We asked for an evaluation of the Ethics and Research Committees of the University Center for Health Sciences (CUCS-UdeG), once the study had started, to evaluate compliance with the ethical processes that we followed throughout it. Both Committees reviewed and approved the ethical procedures of the study.

Consent for publication: Not applicable.

Availability of data and materials: The datasets used and/or analyzed during the current study are available from the corresponding author on reasonable request. 
Competing interests: The authors declare that they have no competing interests.

Funding statements: GBGA and CTG received financial support from the National Council for Science and Technology (CONACYT, for its Spanish acronym) through its research staff training grant (CVU -standing for Unique Curriculum Vitae- 780629 and CVU 778870, respectively). MOG, ASR, de A.M. and VB received support from the National System of Researchers (CVU 267588, 38422, 80029 and 22064, respectively).

Authors' contributions: Conceptualization, G.B.G.A, MOG, and V.B.; data curation, G.B.G.A and C.T.G.; funding acquisition, G.B.G.A, M.O.G, S.R.A, C.T.G. A.M and VB; Formal analysis, G.B.GA, S.R.A, C.T.G and A.M., investigation, G.B.G.A and S.R.A.; methodology, G.B.G.A, C.T.G, C.O.M.J and A.M; Project administration, V.B.; software and analysis G.B.G.A, C.T.G, D.M; validation, A.M. and V.M; Supervision, M.O.G and V.B; writingoriginal draft preparation, G.B.G.A, C.T.G, C.O.M.J, and V.B.; writing-review and editing, G.B.G.A, S.R.A, M.O.G, A.M. and V.B.; supervision, M.O.G and V.B. All authors have read and agreed to the published version of the manuscript.

Acknowledgements: We want to thank the students of the Bachelor's degrees in nursing, nutrition, and medicine of the CUCS-UdeG that partook in this research and their teachers who allowed us to participate in class time. We also thank the Research Ethics Committee and the Research Committee, CUCS-UdeG, for their advice and support to guarantee ethical practices and the confidentiality of the information).

\section{Author information:}

Gabriela Alejandra Grover-Baltazar. Student of Public Health PhD, Centro Universitario de Ciencias de la Salud (CUCS), Universidad de Guadalajara (UdeG). Guadalajara, Jalisco. México.

Ana Sandoval-Rodríguez. Instituto de Biología Molecular en Medicina, CUCS-UdeG, Guadalajara, Jalisco, México.

Gabriela Macedo-Ojeda. Instituto de Investigación de Ciencias Biomédicas (IICB), CUCS -UdeG, Guadalajara, Jalisco, México.

Gabriel Chavira Trujillo. Student of Public Health PhD, CUCS-UdeG, Guadalajara, Jalisco, México.

Marco Julián Corona-Ortiz. Technological University Dublin. Dublin Irlanda.

Martha de Alba. Departamento de Sociología. Universidad Autónoma Metropolitana (UAM), Unidad Iztapalapa. Ciudad de México.

Barbara Vizmanos. Instituto de Nutrigenética y Nutrigenómica, CUCS-UdeG, Guadalajara, Jalisco México.

\section{References}

1. World Health Organization (WHO) \& United Nations Children's Fund (UNICEF). Protecting, promoting, and supporting breastfeeding in facilities providing maternity and newborn services: the revised Baby-friendly 
Hospital Initiative 2018 [Internet]. WHO \& UNICEF. Geneva; 2018 [cited 2021 Apr 10]. Available from: https://www.who.int/nutrition/publications/infantfeeding/bfhi-implementation/en/

2. Binns C, Lee M, Low WY. The Long-Term Public Health Benefits of Breastfeeding. Asia Pacific J Public Heal. 2016 Jan 20;28(1):7-14. doi: 10.1177/1010539515624964

3. Chowdhury R, Sinha B, Sankar MJ, Taneja S, Bhandari N, Rollins N, et al. Breastfeeding and maternal health outcomes: a systematic review and meta-analysis. Acta Paediatr. 2015 Dec;104(467):96-113. doi: https://doi.org/10.1111/apa.13102

4. World Health Organization \& United Nations Chikdren's Fund. Global Breastfeeding Scorecard, 2019. Increasing commitment to breastfeeding through funding and improved policies and programmes [Internet]. WHO \& UNICEF. 2019. [cited 2021 Mar 23]. Available from:

https://apps.who.int/iris/handle/10665/326049.

5. Shama-Levy T, Vielma-Orozco E, Heredia-Hernández O, Romero-Martínez M, Mojica-Cuevas J, CuevasNasu L, et al. Encuesta Nacional de Salud y Nutrición 2018-2019: Resultados Nacionales. Cuernavaca, México: Instituto Nacional de Salud Pública; 2020.

6. Gutiérrez JP, Rivera-Dommarco J, Shamah-Levy T, Villalpando-Hernádez S, Franco A, Cuevas-Nasu L, et al. Encuesta Nacional de Salud y Nutrición 2012. Resultados nacionales. Cuernavaca, México:Instituto Nacional de Salud Pública; 2013. Available from: https://ensanut.insp.mx/encuestas/ensanut2012/informes.php

7. Cosío-Martínez TG, Hernández-Cordero S, Rivera-Dommarco J, Hernández-Ávila M. Recomendaciones para una política nacional de promoción de la lactancia materna en México: postura de la Academia Nacional de Medicina. Salud Publica Mex. 2017;59(1):106-13. doi:10.21149/8102

8. de Almeida JM, Luz S, Ued F. Apoio ao aleitamento materno pelos profissionais de saúde: revisão integrativa da literatura. Rev Paul Pediatr. 2015;33(3):356-63. doi:10.1016/j.rpped.2014.10.002

9. Arciniegas Barón M, Henao Molina CY. Represetaciones sociales en lactancia materna en un grupo de 14 mujeres en edad reproductiva de la comunidad educativa de la universidad de la Salle-sede Chapinero. [Master's dissertation]. Bogota, Colombia. Universidad de La Salle; 2014.

10. Hitt R, Zhuang J, Anderson J. Media presentation of breastfeeding beliefs in newspapers. Health Commun. 2018 Oct 3;33(10):1293-301. doi:10.1080/10410236.2017.1351275

11. Vera-Mechán AB. Representaciones sociales de la lactancia materna desde la perspectiva de la madre adolescente. Chiclayo, 2013. [Master's dissertation]. Universidad Católica Santo Toribio de Mogrovejo; 2013 [cited 2019 Mar 17]. Available from: http://tesis.usat.edu.pe/handle/20.500.12423/602

12. Moscovici S. El Psicoanalisis, su imagen y su público. 2nd ed. Finetti NM, editor. Buenos Aires: Huemul; 1979. $366 \mathrm{p}$.

13. Banchs MA. Aproximaciones procesuales y estructurales al estudio de las representaciones sociales. Peer Rev Online J. 2000;9(1):3.1-3.15.

14. Abric J-C. Prácticas Sociales y Representaciones. 1st ed. Dacosta -Chevrel J, Flores-Palacios F, editors. México: Ediciones Coyoacán S.A. de C.V.; 2001. 251 p.

15. Lo Monaco G, Piermattéo A, Rateau P, Tavani JL. Methods for studying the structure of social representations: a critical review and agenda for future research. J Theory Soc Behav. 2017;47(3):306- 
31.

16. Vergès P. L'evocation de l'argent: une méthode pour la définition du noyau central de la représentation. Bull Psychol. 1992;45(105):203-9.

17. Universidad de Guadalajara. Plan de Desarrollo Institucional 2014-2030 [Internet]. Guadalajara, Jalisco; 2014. Available from: http://www.hcgu.udg.mx/sites/default/files/sesiones_cgu/2013-2014/2014-03-24 00\%3A00\%3A00/pdi_2030_21marzo14.pdf.

18. Centro Universitario de Ciencias de la Salud. 1er informe de actividades 2019-2020. Dr. José Francisco Muños Valle CUCS. Informe Técnico [Internet]. Universidad de Guadalajara. Guadalajara, Jalisco; 2019. Available from: https://www.cucs.udg.mx/sites/default/files/informe2019.pdf

19. Otzen T, Manterola C. Técnicas de muestreo sobre una población a estudio [Sampling techniques on a population study]. Int J Morphol [Internet]. 2017 [cited 2019 Apr 29];35(1):227-32. Available from: https://scielo.conicyt.cl/pdf/ijmorphol/v35n1/art37.pdf

20. Marchand P, Ratinaud P. L'analyse de similitude appliquée aux corpus textuels: les primaires socialistes pour l'élection présidentielle française (septembre-octobre 2011). Actes des 11eme Journées Int d'Analyse Stat des Données Textuelles [Internet]. 2012;687-98. Available from: http://lexicometrica.univparis3.fr/jadt/jadt2012/Communications/Marchand, Pascal et al. - L'analyse de similitude appliquee aux corpus textuels.pdf

21. Weller SC. Cultural Consensus Theory: Applications and Frequently Asked Questions. Field methods. 2007 Nov 21;19(4):339-68. doi:10.1177/1525822X07303502

22. Dodou HD, Oliveira TDA de, Oriá MOB, Rodrigues DP, Pinheiro PN da C, Luna IT. Educational practices of nursing in the puerperium: social representations of puerperal mothers. Rev Bras Enferm. 2017 Dec;70(6):1250-8. doi:10.1590/0034-7167-2016-0136

23. Pérez Bravo MD, Moreno Hernández A. Dando voz a las mujeres: representaciones sociales y experiencias sobre la lactancia. Dossiers Fem. 2017;22(22):107-17. doi:

http://dx.doi.org/10.6035/Dossiers.2017.22.7

24. Jara-Palacios MÁ, Cornejo AC, Peláez GA, Verdesoto J, Galvis AA. Prevalence and determinants of exclusive breastfeeding among adolescent mothers from Quito, Ecuador: a cross-sectional study. Int Breastfeed J. 2015 Dec 10;10(33). doi:10.1186/s13006-015-0058-1

25. Victora CG, Bahl R, Barros AJ, França G V, Horton S, Krasevec J, et al. Breastfeeding in the 21st century: epidemiology, mechanisms, and lifelong effect. Lancet. 2016 Jan;387(10017):475-90. doi:10.1016/S0140-6736(15)01024-7

26. World Health Organization \& Pan American Health Organzation. Breastfeeding- Benefits [Internet]. World Health Organization; 2020 [cited 2020 May 30]. Available from: https://www.paho.org/hq/index.php? option=com_content\&view=article\&id=9328:breastfeeding-benefits\&ltemid=42403\&lang=en

27. Bucher MK, Spatz DL. Ten-Year Systematic Review of Sexuality and Breastfeeding in Medicine, Psychology, and Gender Studies. Nurs Womens Health. 2019;23(6):494-507. doi:10.1016/j.nwh.2019.09.006

28. Giordani RCF, Piccoli D, Bezerra I, Almeida CCB. Maternidade e amamentação: identidade, corpo e gênero. Cien Saude Colet. 2018;23(8):2731-9. doi: 10.1590/1413-81232018238.1412016 
29. Swanson V, Hannula L, Eriksson L, Wallin MH, Strutton J. 'Both parents should care for babies': A crosssectional, cross-cultural comparison of adolescents' breastfeeding intentions, and the influence of shared-parenting beliefs. BMC Pregnancy Childbirth. 2017;17(1):204. doi: 10.1186/s12884-017-1372-y

30. Wallenborn JT, Chambers GJ, Masho SW. The Role of Paternity Acknowledgment in Breastfeeding Noninitiation. J Hum Lact. 2018;34(4):737-44. Doi. doi:10.1177/0890334417743209

31. Sayres S, Visentin L. Breastfeeding: uncovering barriers and offering solutions. Curr Opin Pediatr. 2018;30(4):591-6. doi:10.1097/MOP.0000000000000647

32. Meek JY, Young M, Noble L, Calhoun S, Dodd S, Elliott-Rudder M, et al. Educational Objectives and Skills for the Physician with Respect to Breastfeeding, Revised 2018. Breastfeed Med. 2019;14(1):5-13. doi: 10.1089/bfm.2018.29113.jym

\section{Figures}




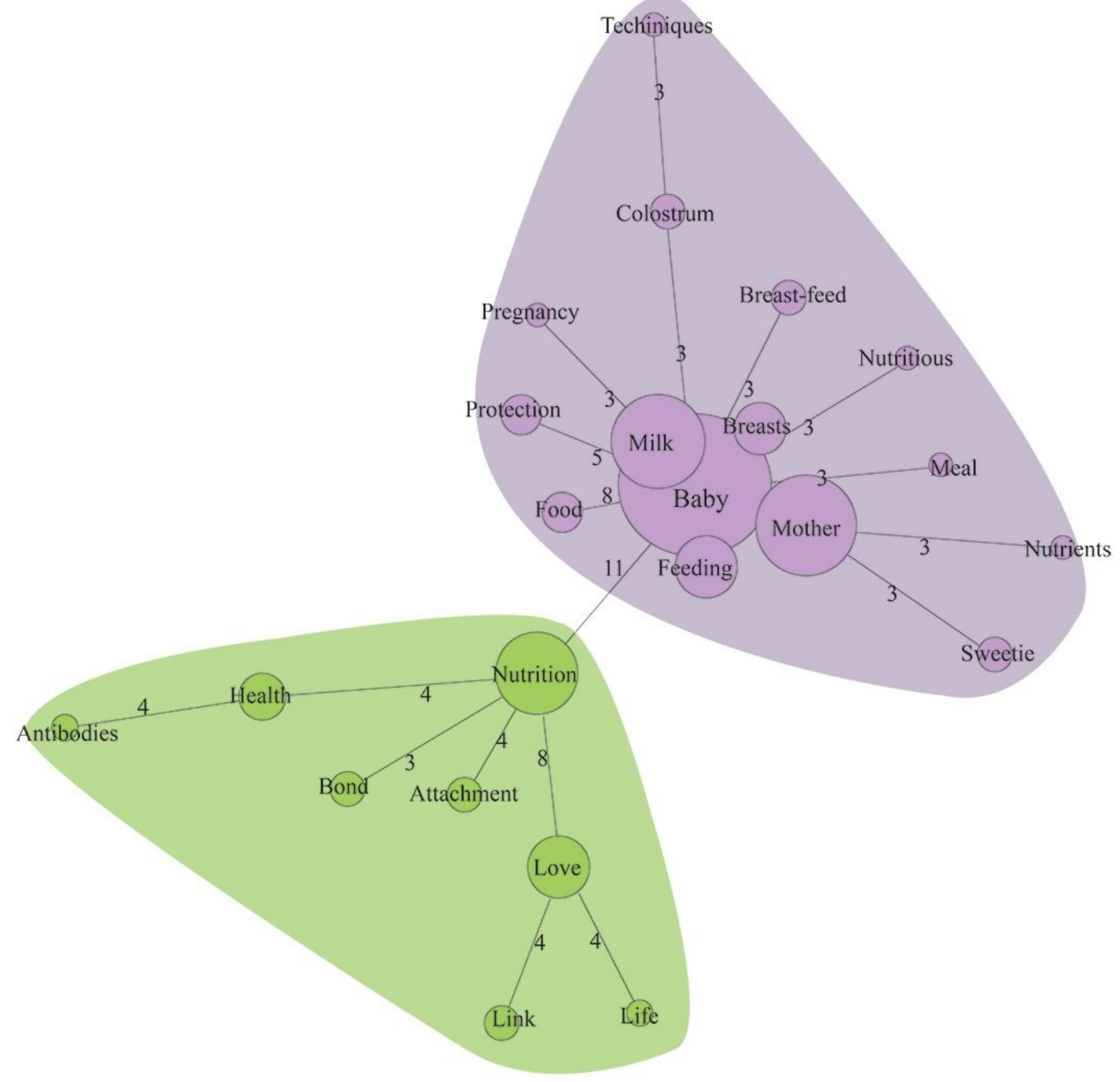

\section{Figure 1}

Graphic representation of the similitude of the words related to breastfeeding. 


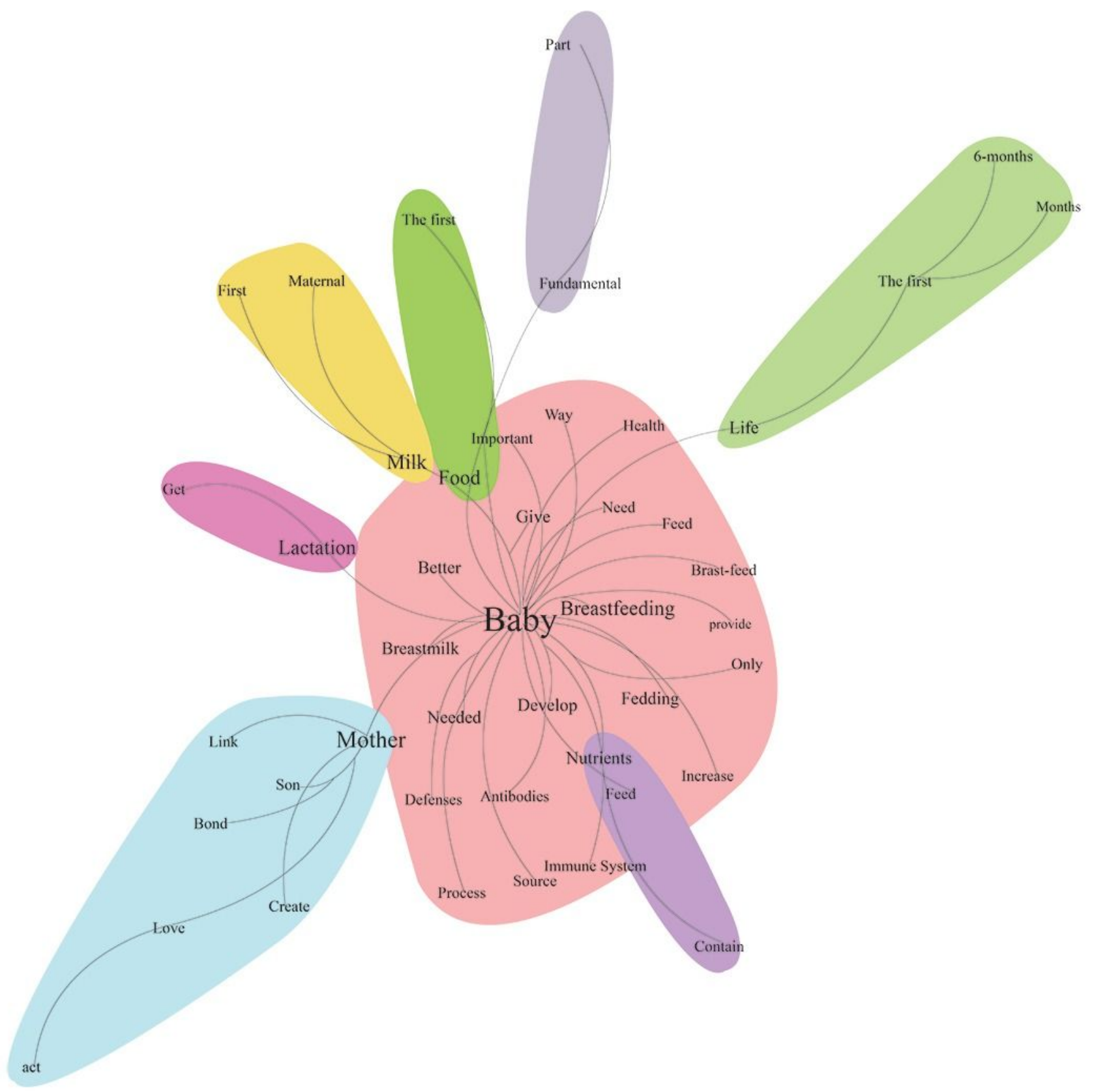

\section{Figure 2}

Graphic representation of the meaning of the words related to breastfeeding. 


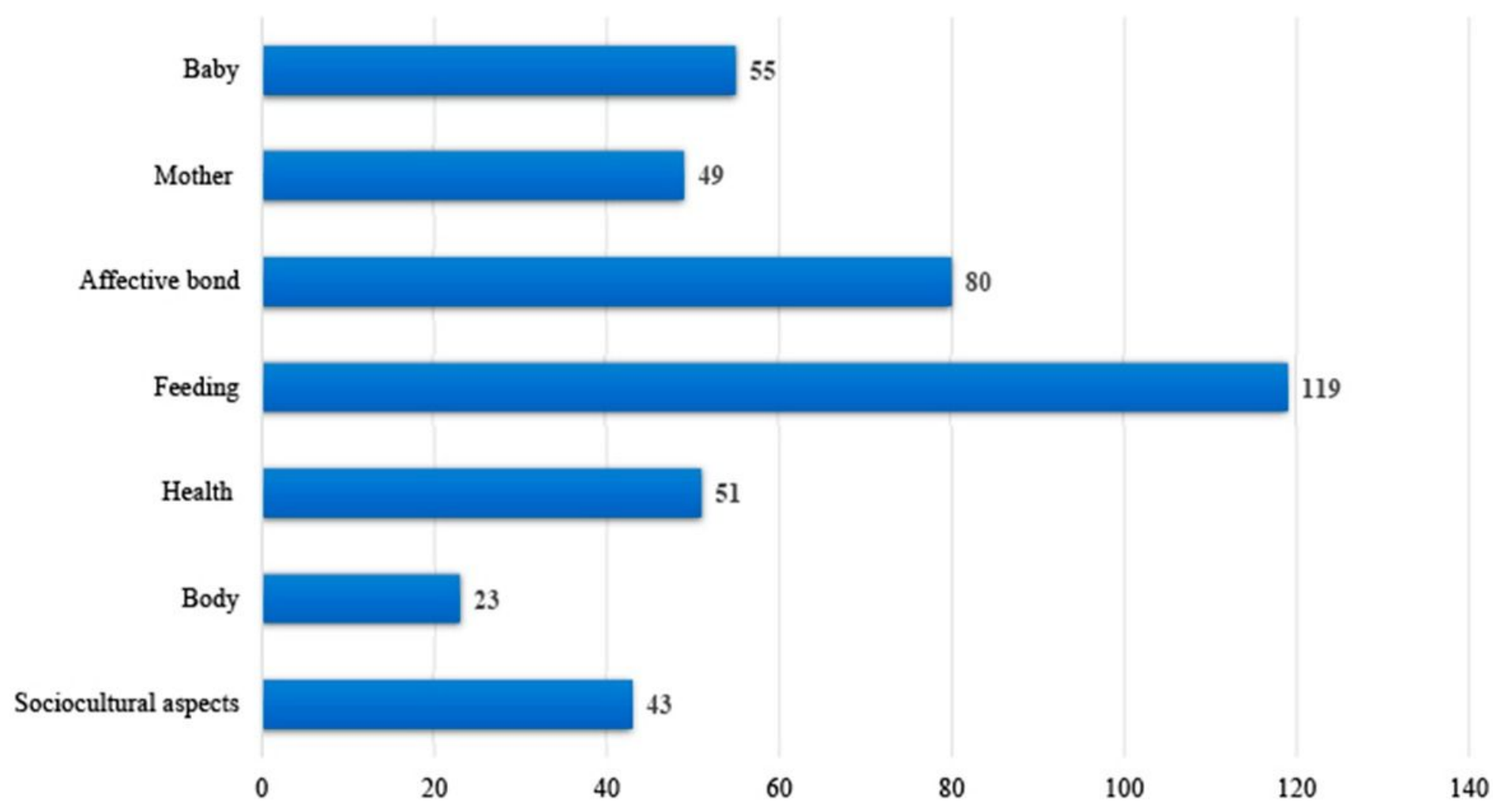

\section{Figure 3}

Thematic categories of the social representations of breastfeeding in health student. Legend: The weight of each category is the total number of words that have been mentioned. 